\title{
Innovation policy of European chemical companies with special focus on large companies
}

\author{
Supriyo Das, Ignasi Brunet Icart
}

\begin{abstract}
According to Arora et alii (1998), the chemical industry is one of the largest and most RED-intensive manufacturing sectors in all the advanced economies, and its innovative patterns and productivity growth processes can have profound impacts on economic growth as a whole. The European chemical industry supplies virtually all sectors of the economy and accounts for $17.8 \%$ of the total sales of chemicals in the world. This paper gives an overview of the European chemical industry and the changing scenario of the world chemical industry by focusing on the top fifteen chemical companies in Europe. It describes the current problems this industry is facing in Europe especially after the economic crisis and shows that the region and the top companies are investing in $R E D$ to bring about innovation and overcome the current challenges. It shows that RED spending in absolute terms has hardly changed over the years and that the industry is still globally the largest investor in RED activities. In terms of RED, BASF has made the greatest investment followed by Bayer and Syngenta, while RED intensity is highest for Syngenta and Bayer. BASF and Bayer have made most patent applications and have also had the highest number of patents granted. The quality of research in most chemical companies is very high and most of the large European companies make their first patent application in Europe rather than elsewhere. All the large chemical companies use Merger E Acquisition (MEA) to gain access to innovation. Industry-academia collaboration is one way to generate innovation in the chemical industry in Europe. Chemical clusters and the geographical distribution of chemical companies play a significant role in generating innovation.
\end{abstract}

Keywords: Chemical industry, Research E development, Innovation, Patenting in the chemical industry. 


\section{Introduction}

The European chemical industry is key to economic development and wealth. It creates modern products and materials, and provides virtually all sectors of the economy with technical solutions (Arora et alii, 1998). The European chemical industry supplies virtually all sectors of the economy and accounts for $17.8 \%$ of the total sales of chemicals in the world (Cefic, 2014). It is one of the largest and most R\&D-intensive manufacturing sectors in all the advanced economies, and its innovative patterns and productivity growth processes can have profound impacts on economic growth as a whole. In a recent study, Tullo (2013) shows that 19 of the top 50 global chemical companies are headquartered in Europe (Table 1) and they make $14.5 \%$ of all sales of chemicals in the world. The purpose of this paper is to provide an overview of the status of the European chemical industry and the problems it currently faces. According to specialists, innovation and research are key to securing the future of the European chemical industry. Research and development is one way in which companies can ensure future growth by developing new products or processes to improve and expand their operations. The paper discusses investment in research and development in the European chemical industry in general and also in the top fifteen European chemical companies in particular. In order to understand research strategy and trends in innovation, we analyze R\&D investment, the patent landscape, university-industry collaboration and the regional distribution of chemical companies.

\section{Problems of the European chemical industry}

Over the years, the European chemical industry has shown considerable resilience, strength and adaptability. In 2007, 12 of the 30 leading chemical companies in the world were headquartered in Europe, representing 10 percent of the world's sales of chemicals while in 2012, 11 of the top 30 global chemical companies were from Europe (Cefic, 2013). Like virtually every other industry worldwide, the European chemical industry has felt the full force of the recent global recession. At its lowest point in March 2009, the industry saw a monthly year-on-year decline of 13.2 percent, a figure that if annualized would represent an output decline of approximately EUR 56 billion (Cefic, 2013). In Europe, the chemical industry saw massive reductions in demand for plastics, paint and man-made fibers, especially in key markets such as automotive and construction. This fall in demand led to severe destocking by many companies, some of which saw their own output decline by 30 to 60 percent. Many large companies are finding major 
credit lines both difficult and expensive to obtain. The European chemical industry is currently facing the unprecedented challenges of strong competition from emerging countries, notably Asia, the Middle East and Russia; and the decline in their share of world chemical sales from $29.8 \%$ in 2001 to $17.8 \%$ in 2012, which means a $34 \%$ decline over a period of 10 years (figure 1).

Figure 1. Contribution of each region

to global chemical sales for the year 2001 and 2012

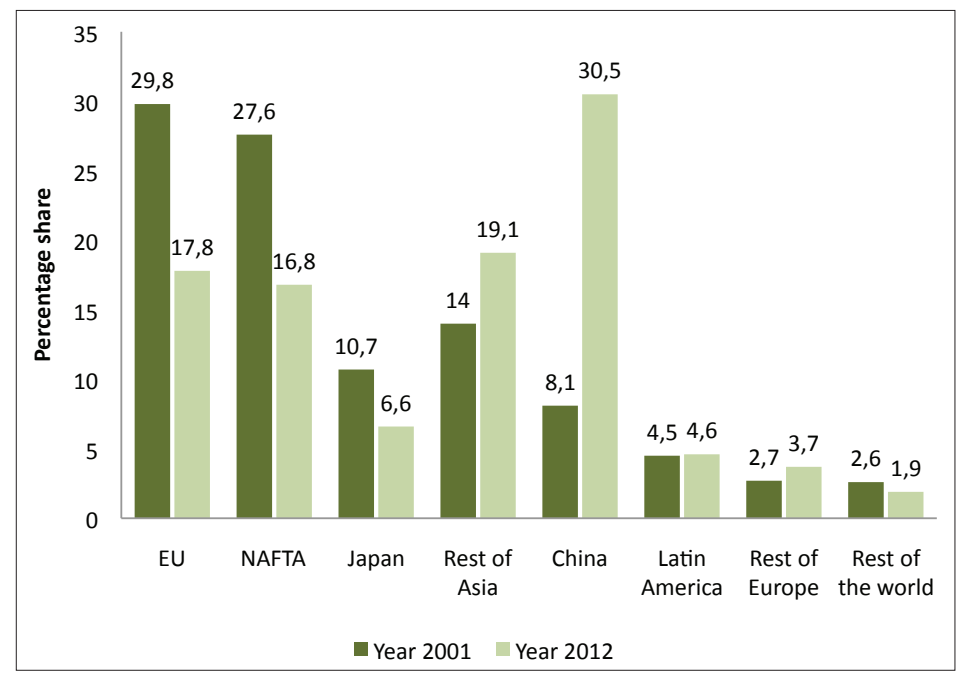

Source: Cefic (2014)

The graph below (figure 2) shows that even though EU sales of chemicals have increased over time, the world market share has decreased so the sales of other areas have increased at a much faster rate. 
Figure 2. EU chemical sales over time and the declining percentage of total world shares

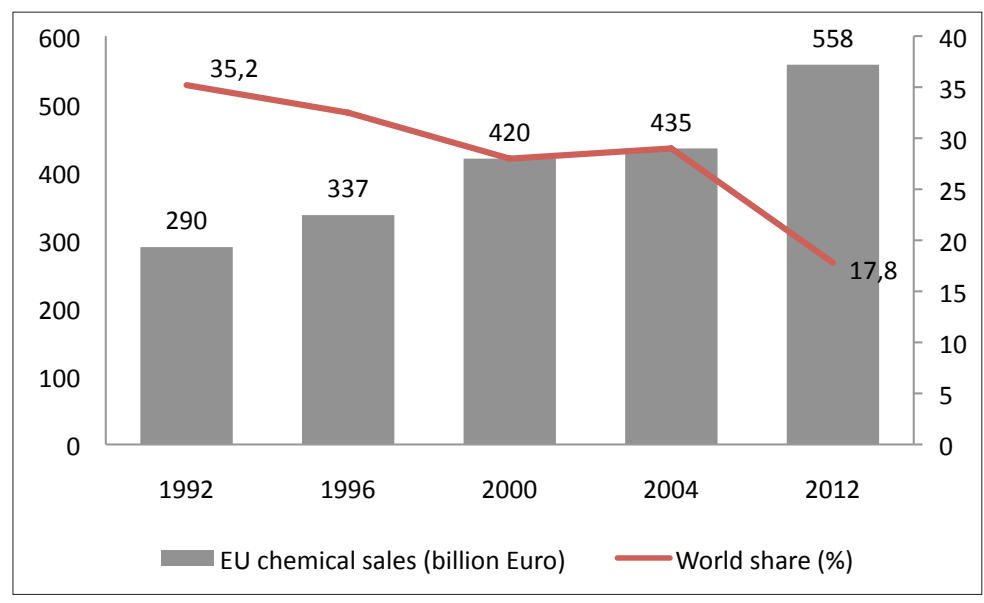

Data source: Cefic (2014)

Although Europe is losing its position in terms of global sales of chemicals, in terms of trade balance it is doing well: exports are 7\% higher than imports. Although Asia is reducing the gap between exports and imports, it is still importing more than it is exporting (figure 3 ).

Figure 3. The export and import of chemical products for different regions

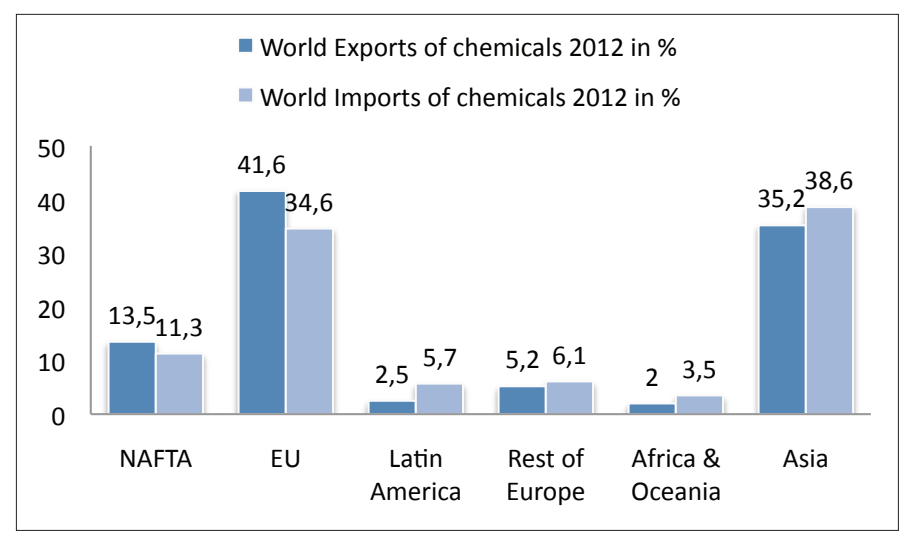

Source: Cefic (2013)

Figure 4 shows how the global market share of the chemical industry changed from region to region between 2002 and 2012. Neither the EU nor NAFTA 
have the largest percentage share any longer. They have been surpassed by China and the rest of Asia.

Figure 4. Distribution of sales of chemical products over different regions

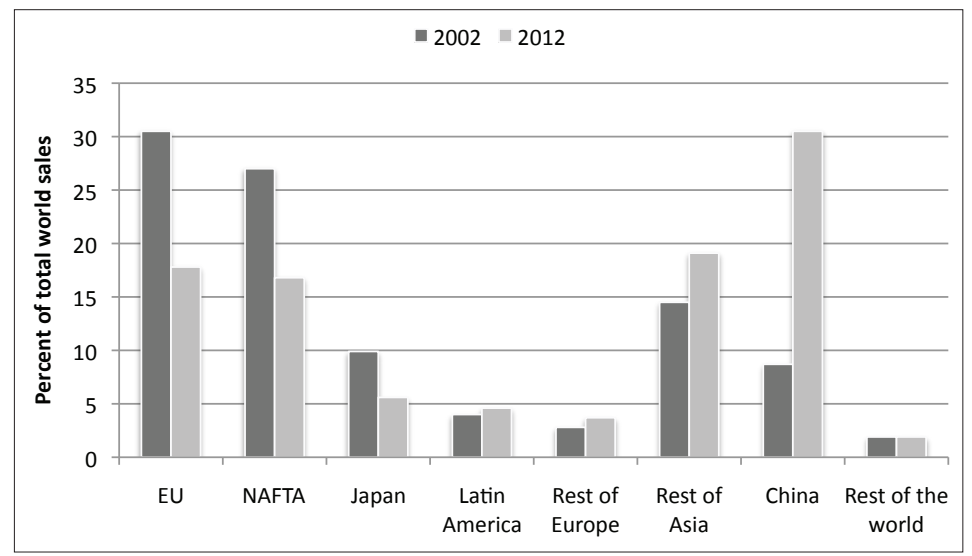

Data source: Cefic (2013). Author's calculation and graph

In 20 years, the EU's share of the chemical market nearly halved. In 1991 the European Union was in a much stronger position than in 2011 with sales of $€ 295$ billion, 36 per cent of world sales in terms of value. Sales constantly grew throughout this period, the total increase being $83 \%$. However, the level of world chemical sales increased threefold in the same period (€819 billion in 1991 and $€ 2744$ billion in 2011). As a consequence, the EU chemicals market share nearly halved in 20 years, from 36 per cent in 1991 to 20 per cent in 2011 (based on raw data in Cefic, 2013).

\section{Objective of the current research}

The objective of the current research is to determine the innovation policy of large European chemical companies. To do so, we first provide an overview of the European chemical industry and then focus on the following questions:

i) What is the trend in innovation in large chemical companies in Europe?

ii) What determinants or variables drive the innovation policy of these large chemical companies? 


\section{Literature review}

The first part of the research consisted of making a review of the literature so that we could understand the work that has been done in the past. Even though innovation in the chemical industry has clearly fallen and subsequently risen, there is no great theoretical understanding of the input variables and macro-and micro-economic determinants of this trend in large chemical companies.

Achilladelis et alii (1990) examined the mechanisms and dynamics of the process of innovation in the chemical industry. Quinn (1983) stated that innovation processes can be chaotic, but need to be managed well if the end results are to be achieved. Johnson (2001) studied the process of innovation and showed how a big organization with a significantly large infrastructure can generate innovation internally. He described five different forms of innovation in a company. Dal Pont et alii (2013) made a similar attempt to define innovation in the chemical sector. Likewise, Hutcheson et alii (1996) focused on sources of technical innovation in the network of companies supplying chemical process plants and equipment. They found out that alliances between contractors and equipment manufacturers not only help to reduce plant design, procurement and erection costs, but also counter the competitive threat from more specialist firms (particularly the large equipment manufacturers that have their own project contracting skills). Furthermore, their study showed that "collaborative innovation" can generate a technological competitive advantage, whilst sharing cost and risk. Abratt and Lombard (1993) studied 51 specialty chemical firms in South Africa to identify the major determinants of product innovation in the specialty chemicals industry. The result showed that innovation in these firms is customer driven, but that there are deficiencies in product predevelopment activities, attention paid to marketing, and the synergy with existing technologies. The drawback of this research is that it does not provide a recipe for product innovation success and the solution found by each firm will depend ultimately on their own external and internal environments.

The latest study by Dal Pont et al (2013) discusses the sequence of innovation of a large chemical company. Ren (2009) made a similar study which built a chart showing the relation between the innovators in the petrochemical industry. Stetter and Lieb (2000) produced a historical over-view of innovation in the crop protection industry from its beginnings to the present day and attempted to show how the research-based crop protection industry was prepared for current and future challenges. They devoted a considerable amount of space to trends in research. Fagerberg (2003) shows the trend of citation and publication in innovation-related topics. Chesbrough showed that large chemical companies 
evolved from closed to open innovation structures as they went global in their R\&D activities (2003). Several studies have been made on the European chemical industry and innovation in economically difficult situations. Colombo (1986) appraised the perspectives of the European chemical industry at a time of economic crisis when the forecast rates of economic growth for the next two decades were continuing to decline. He examined the key issues in the chemical industry: its changing geography, industrial redeployment, the change from product chemistry to function chemistry, and the problems of scientific and technological innovation and its consequences for industry and society. Cooper and Kleinschmidt (1993) found what separated new-product winners from losers in a chemical industry and stated that the key to new-product success was the quality of the activities in the innovation process, early and sharp project and product definition, a strong team leader together with an accountable, multidisciplinary team. Earlier, Colombo (1980) claimed that the chemical industry was an inherently innovative industry and highlighted key innovation in the chemical industry between 1930 and $1970 . \mathrm{He}$ also focused on constraints or barriers to innovation in the chemical industry. Walsh (1984) studied the determinants of the rate, direction and scale of invention and innovative activity in the chemical industry over the period 1930-1980 and his findings suggested that the importance of both "demand pull" from the customer and "discovery push" from the R\&D are equally important for invention and innovation in the chemical industry. A. T. Kearney (2012) stated that most of the growth in the previous 25 years had been driven by Asia, which now makes almost half of the global chemical sales. They also predicted that such key end markets of the chemical industry as automotion, construction and pulp production were all set to surge in Asia, and drive the growing local demand for chemicals. The indications are that Europe may become the global pressure point for plant closures.

The European Commission' Enterprise and Industry study (2009) made some suggestions for bringing innovation to the European chemical industry. The main ones were: a more sustainable use of resources, innovation networks, cross-cutting chemical solutions throughout the value chains, the quality and quantity of $R \& D$ and the effectiveness of innovation, intellectual property, fighting against counterfeiting, regulations in the chemical industry, education and attracting new talent to the chemical industry. Specialchem (2012) showed the challenges of new business development and how to set about it. Arvanitis and Villavicencio (2000) gave an overview of the chemical innovation system of industrialized countries and Mexico. Only 12 per cent of the companies surveyed 
introduced new products not existing elsewhere, so the vast majority of chemical companies are moderate innovators that mainly aim to copy or adapt already known products. In the case of Mexican chemical companies, 18 per cent do not spend anything on innovation, 39 per cent spend less than 2 per cent of their sales and more than 40 per cent of the companies spend more than 2 per cent of their sales on R\&D. The study by Heinzelbecker (2005) was about the future of the European chemical industry with particular focus on innovation in order to remain competitive. Ren (2009) established the typical sequence of innovation as seen in the chemical industry.

\section{Methodologies}

In order to understand the state of the European chemical industry and the issues it is facing, we used the previous literature, and the data from the European chemical agency and individual countries' chemical and R\&D agencies. The previous literature indicated that patent data is the key indicator of innovation. According to the literature review, the indicators that might have an influence on innovation in the chemical industry in Europe are research and development spending, merger and acquisition deals, inter-industry and industry-academic research collaboration, chemical clusters and geographic distribution of chemical companies.

The research consists of two steps which can be further divided into several sub steps.

\subsection{Data collection}

Financial and non-financial data about innovation in the European chemical industry were collected for the last 5-10 years. Table 1 shows the top nineteen chemical companies according to the existing literature, company reports and various economic databases. 
Table 1. The top 19 chemical companies in Europe for the year 2012

\begin{tabular}{|c|c|c|c|c|c|}
\hline & Company & Headquarters & & Company & Headquarters \\
\hline 1 & BASF & Germany & 11 & Yara & Norway \\
\hline 2 & Shell & Netherlands & 12 & DSM & Netherlands \\
\hline 3 & LyondellBasell & Netherlands & 13 & Lanxess & Germany \\
\hline 4 & Bayer & Germany & 14 & Syngenta & Switzerland \\
\hline 5 & Ineos Group & Switzerland & 15 & Borealis & Austria \\
\hline 6 & AkzoNobel & Netherlands & 16 & Arkema & France \\
\hline 7 & Air Liquide & France & 17 & Eni & Italy \\
\hline 8 & Evonik & Germany & 18 & Styrolution & Germany \\
\hline 9 & Solvay & Belgium & 19 & Total & France \\
\hline 10 & Linde & Germany & & & \\
\hline
\end{tabular}

Data source: Tullo (2013). Table drawn up by the author

The innovation determinants and variables of these nineteen companies can be obtained from the following sources:

$+\quad$ Patents

The historical data on patent publication, a strong indicator of innovation, was collected from the "Thomson innovation" database which is an intellectual property and IP collaboration platform that publishes statistics about patents.

+ Investment in R\&D

Information about investment in R\&D can be found in companies' annual reports published online.

- Merger and acquisition and the restructuring of large chemical companies This information can be obtained from the industrial literature, and such websites as Thomson Reuter and IHS Global Insight, which publish specific large company reports.

- Research outcome of large chemical companies collaborating with top universities and institutes

This information can be obtained from the European Community Research and Collaboration Database and also from the industrial innovation databases of individual countries.

- Geographical location and availability of people with the right sets of skills 
This information is available in the literature and also from the website

Chemical Parks in Europe and the European chemical cluster database.

In the second step of the research, the data is subject to statistical analysis and conclusions are drawn.

\subsection{Data analysis}

To understand the various trends, the data was analyzed using Microsoft Excel. Time series analyses were carried out and correlations determined using the JMP statistical software from SAS.

\section{The European Chemical Industryः An Overview}

The European chemical industry is a robust, world-leading sector in terms of productivity and employment. But it is also at the root of all other industries. The European chemical industry is based on the following six categories of products: basic chemicals, specialty chemicals, petrochemicals, polymers, pharmaceuticals and consumer chemicals. The industry has an extremely broad range of customers. Only $30 \%$ of the combined output of the chemical and pharmaceutical industries is sold to private households and other end users.

\section{Figure 7: The product mix of the European chemical industry}

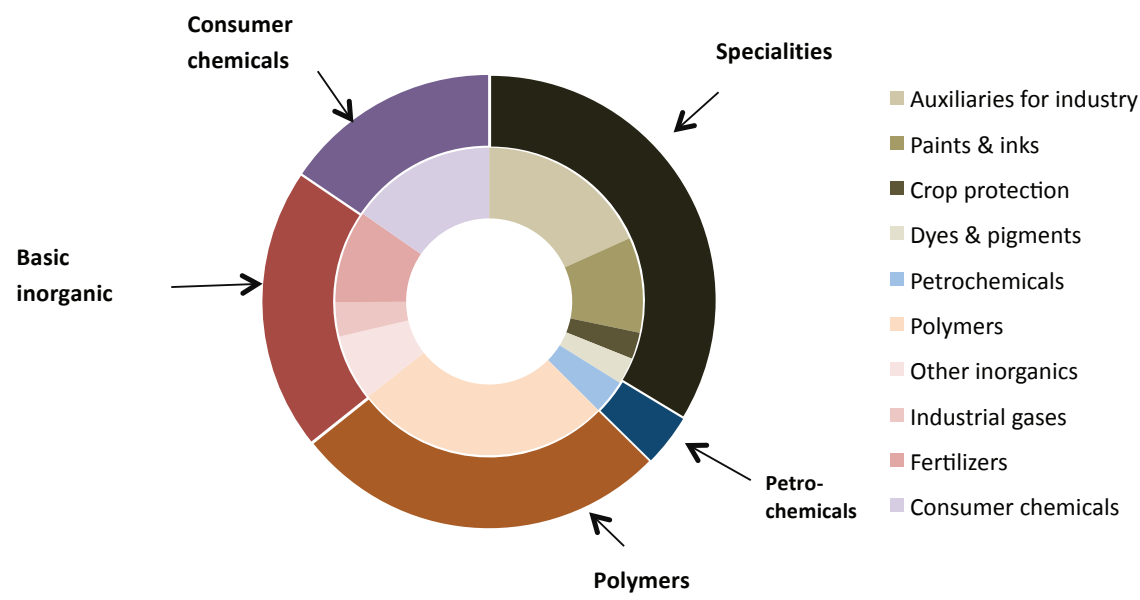

Data source: Cefic (2014). Graph: Author

With a workforce of 1.2 million and sales of $€ 642$ billion, it is one of the biggest industrial sectors and an important source of direct and indirect employment in 
many regions of the European Union (Cefic, 2013). Figure 8 below shows how the direct work force is distributed among the various products. It can be seen that the bulk of the work force is employed in producing basic chemicals and related products.

\title{
Figure 8: Percentage of employees in each sector of the European chemical industry
}

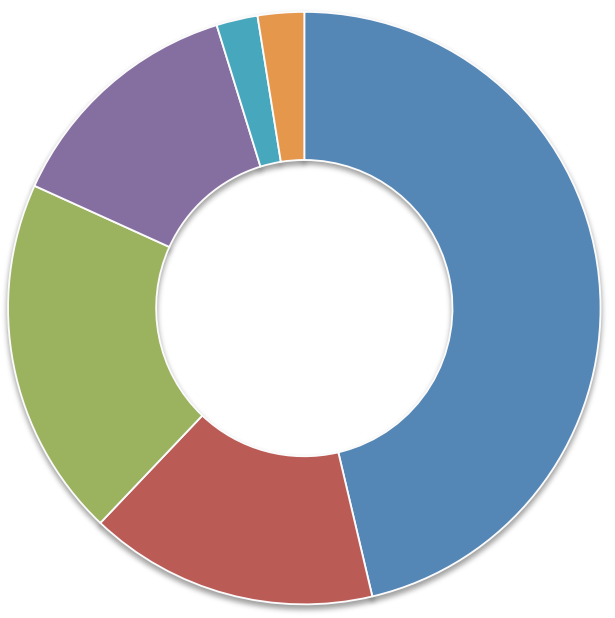

\author{
Basic chemicals, fertilisers and nitro \\ gen compounds, plastics and synth \\ etic rubber in primary forms \\ - Other chemical products \\ - Soap and detergents, cleaning and \\ polishing preparations, perfumes a \\ nd toilet preparations \\ - Paints, varnishes and similar coatin \\ gs, printing ink and mastics \\ Pesticides and other agrochemical \\ products \\ Man-made fibres
}

Data source: EUROSTAT (2013). Graph: Author

Most European chemical companies are located in seven EU countries: Germany, France, Italy, UK, Netherlands, Spain and Belgium. Of these, Germany has most with more than 140,000 companies followed by France and Italy.

In the EU, there are around 29,000 semi-medium, medium and large chemical companies which employ a total staff of about 1.2 million. This is equivalent to $4 \%$ of the manufacturing industry's overall workforce. Employment in the industry has decreased by $2 \%$ annually over the past ten years. A total of $4 \%$ of all chemical companies have more than 250 employees and these are responsible for $72 \%$ of all sales and $65 \%$ of total employment (EUROSTAT, 2013). They make a major contribution to the transfer of innovation generated upstream in the chemicals value chain to downstream manufacturing industry. As producers of basic and specialty chemicals, large chemical companies often supply SMEs and are sources of innovation. 
Figure 9. The number of chemical companies in EU countries

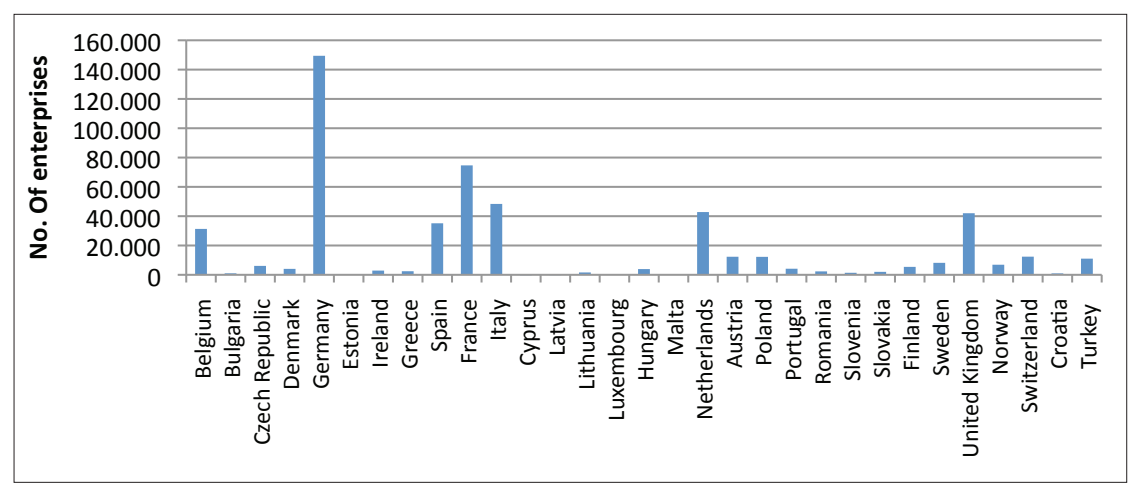

Data source: EUROSTAT (2013). Graph: Author

Figure 10: The percentage of different-sized companies in Europe

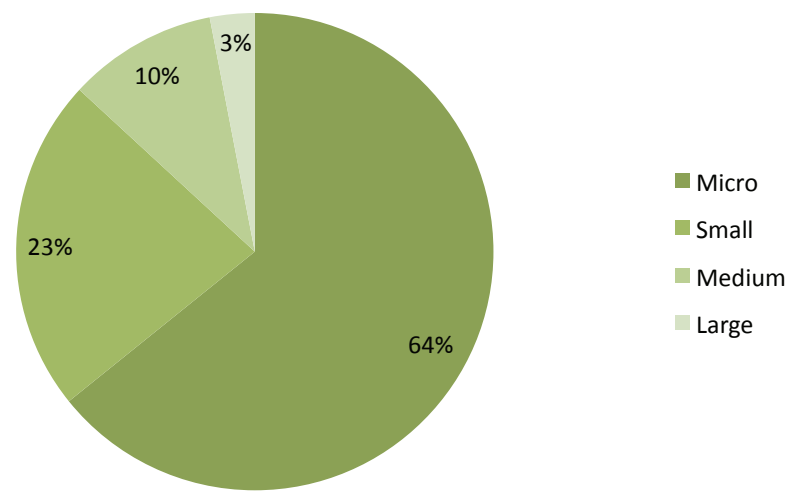

Data Source: EUROSTAT (2013). Graph: Author

Even though large chemical companies are only $3 \%$ of the total number of chemical companies, they make a significant contribution because they are the largest supplier of products and also the biggest employers. The companies are classified as one size or another on the basis of the following criteria:

- small enterprises: 10-49 employees

+ medium-sized enterprises: 50-249 employees;

+ large enterprises: 250 or more employees. 
Figure 11. The value addition of different sizes of EU companies and the number of employees in each size

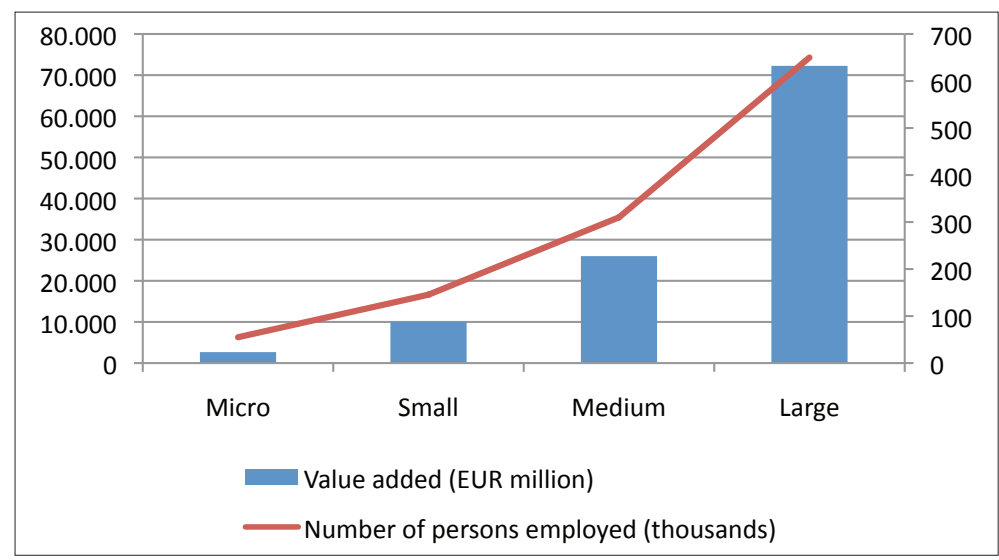

Data Source: EUROSTAT (2013). Graph: Author

Figure 11 shows that large chemical companies in Europe bring most value to the chemical industry and justify the focus of the current research.

Figure 12. Distribution of world's top 50 chemical companies according to geographical regions

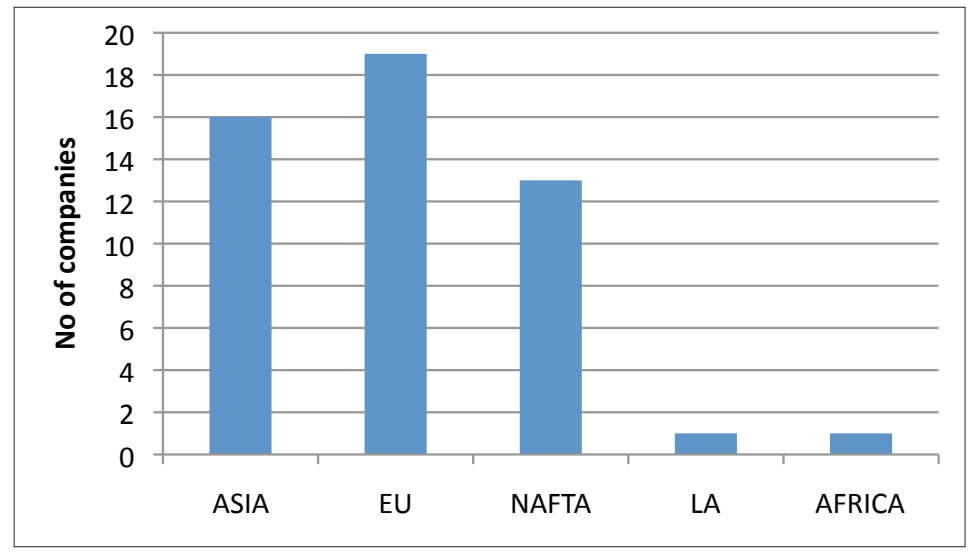

Data source: Tullo (2013). Author's calculation and graph

The chart above (figure 12) shows the distribution of the world's top 50 chemical companies according to geographical regions. It is interesting to see that the EU is still home to most of them, with 19 headquartered in this region followed by Asia with 16 . 


\section{Innovation trend of the top European companies in terms of patenting activity}

Patents are undoubtedly one of the instruments that firms use to capture income from innovation. Of the few indicators on technology output that are available, patent-based indicators are probably the most frequently used. The most commonly used indicators are counts of patent families that share a number of common elements. This section studies the patent landscape of the top chemical companies in Europe. The list of the top nineteen chemical companies includes three oil companies. So as not to mix up chemical patents with other patents, these three companies are ignored in this study.

Figure 13 compares the patents granted to the chemical and chemicalrelated industry with other leading industries in Europe (electrical engineering, instrumentation and mechanical engineering. The bar graph shows that mechanical engineering has the highest number of patents granted while chemical engineering and electrical engineering are a little behind in second and third place. It also shows that the number of patents granted to the chemical industry was lowest in 2009, which is when the global economic crisis hit and the chemical industry was badly affected.

Figure 13. Number of patents granted by the European Patent Office to various sectors

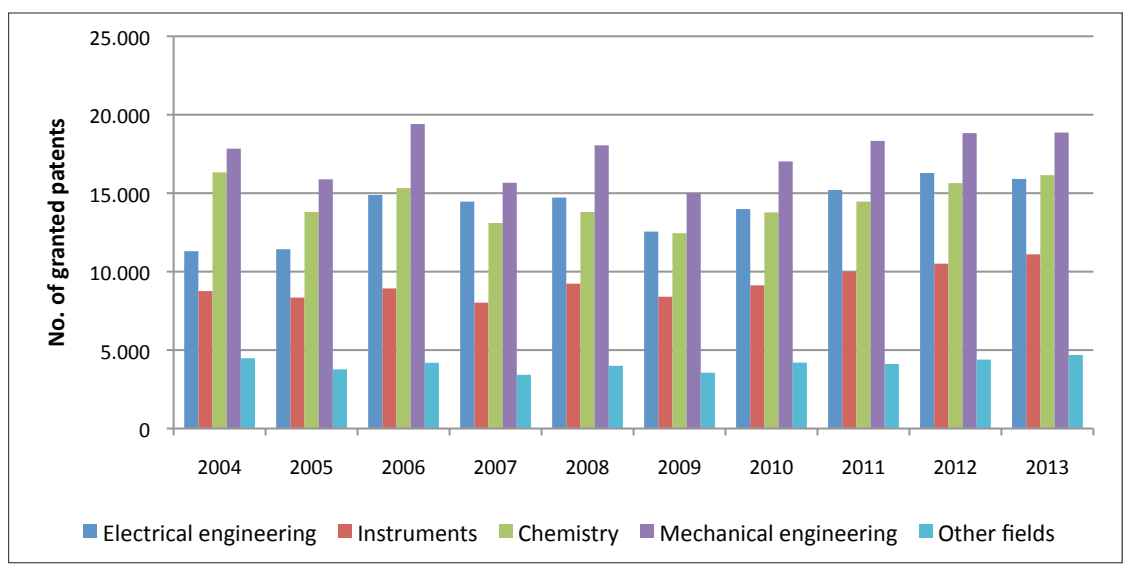

Data source: European Patent Office (2014). Graph: Author 
According to the European Patent office, the chemical or chemical engineering sector consists of eleven subsectors. Figure 14 shows how the total number of patents granted for 2013 were distributed among various sub-sectors. Fine organic chemistry has the highest share of chemistry patents followed by pharmaceuticals and bio-chemistry. We shall further discuss patenting in this sector below. Patents in the basic materials sector also make a significant contribution to the total number of patents. On the other hand, research into food chemistry, environmental technology and nanotechnology was insignificant.

Figure 14. Patents granted by the European Patent Office to various sub sectors of the chemical industry in the year 2013

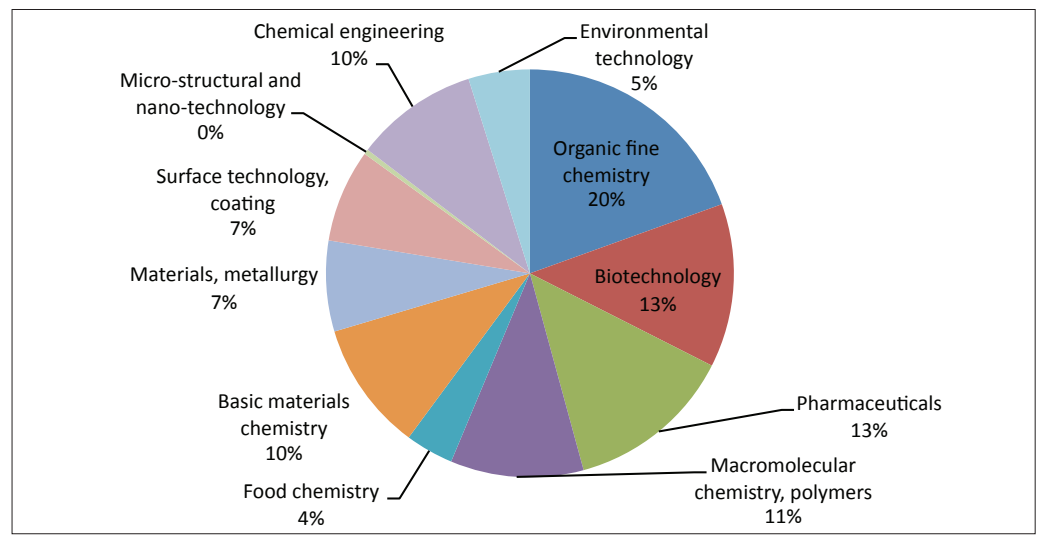

Data source: European Patent Office (2014). Graph: Author

Figure 15 shows the patent applications made by these companies to the leading patent authorities throughout the world over the last ten years. In order to avoid counting the same patent applied for in two countries more than once, we counted patent families instead of the number of actual patents. A patent family is a set of patents taken out in various countries to protect a single invention (when the initial application in one country - the priority - is then extended to other countries). In other words, a patent family is the same invention disclosed by a common inventor(s) and patented in more than one country. BASF, Bayer and Lyondell Basel are the leading applicants. All other companies made considerably fewer applications, while Solvay showed an upward trend. So these three companies are at the forefront of research and development. 
Figure 15. Global patent application and publication of patent-related documents

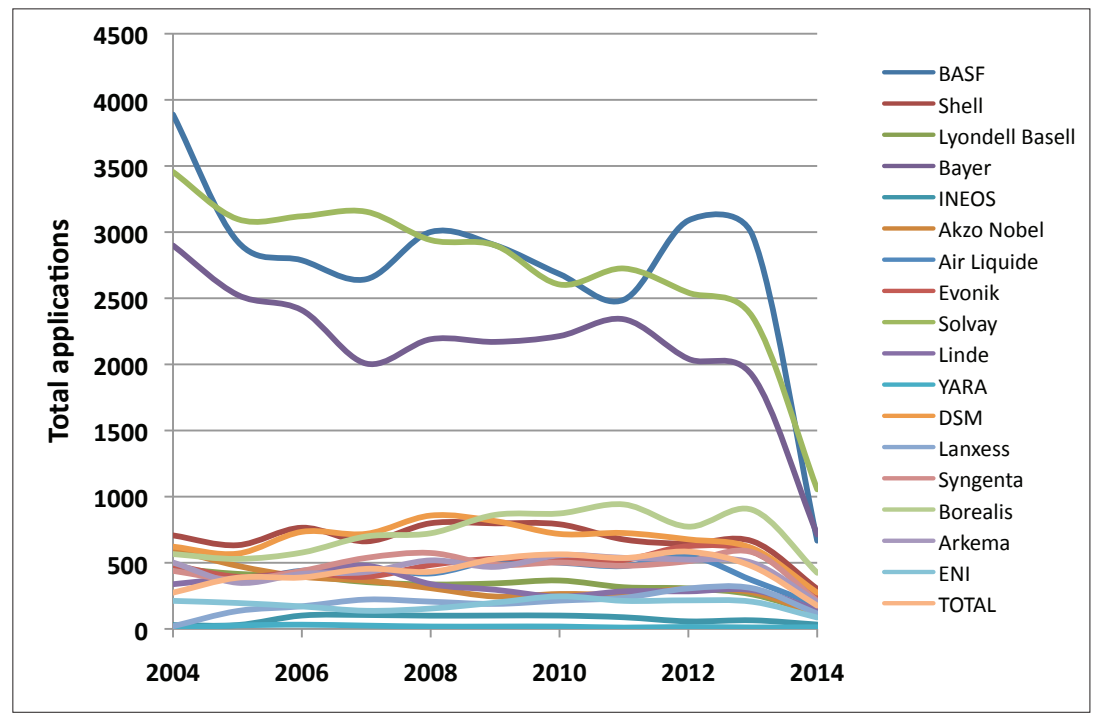

Data source: Thomson Innovation (2014). Author's analysis

The graph below (figure 16) shows the number of patent families granted to the top fifteen chemical companies in Europe. The patents granted were searched for in the database of the most important patent authorities: US, Europe, Australia, Canada, Germany, China, India, Japan, Korea, Singapore and Vietnam. On the basis of the patents granted, the companies can be divided into highly patenting companies, medium patenting companies and low patenting companies. BASF has highest number of patents granted followed by Bayer. Likewise, in both cases, there was a fall in the number of patents granted between 2004 and 2009. Then they seem to have recovered. For the year 2014, we have considered data until the middle of the year. Many of the companies fall in the range of 150 to 250 patents granted, which we can consider as medium innovative companies. In this study we also found some companies that have paid very little attention to patents, and have, therefore, had very few patents granted. 
Figure 16. Patents granted to the top chemical companies by the leading patent offices

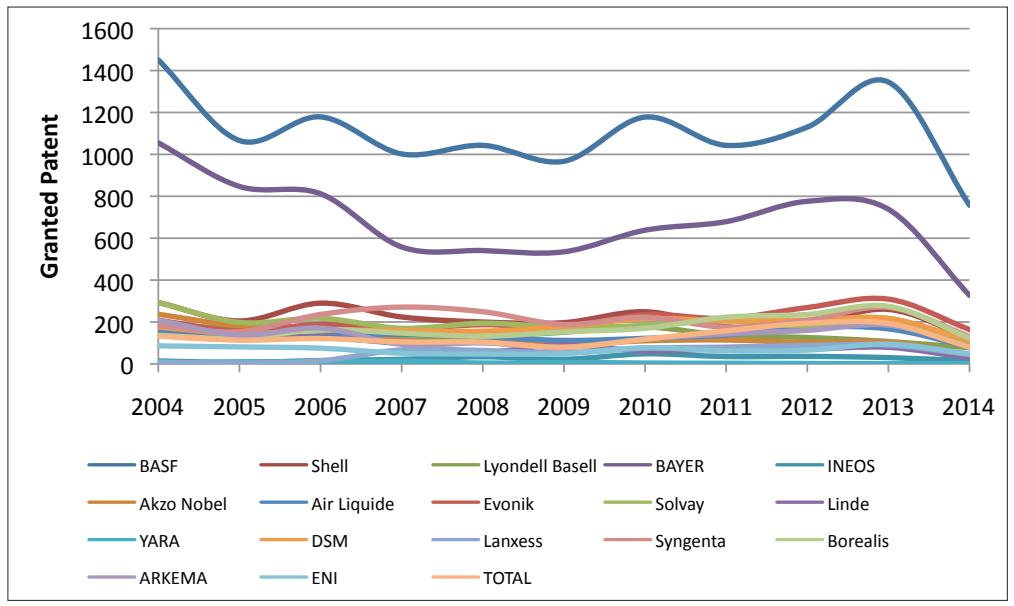

Data source: Thomson Innovation (2014). Author's analysis

It is generally believed that the more research companies do, the more patent applications they will make. It is also believed that the quality of research can be judged by the number of patents granted. Graph 14 below shows the ratio of patents granted to patents applied for in one particular year. It can be seen that in most cases the ratio is between 0.5 and 1.5 , which suggests that both the research and the patent applications are of high quality. In many cases the ratio is above one. This is because a patent application can take a few years before it is granted. So in some cases the number of patents granted is higher than the number applied for in one particular year. 
Figure 17. Ratio of applications to patents granted for the top chemical companies in Europe

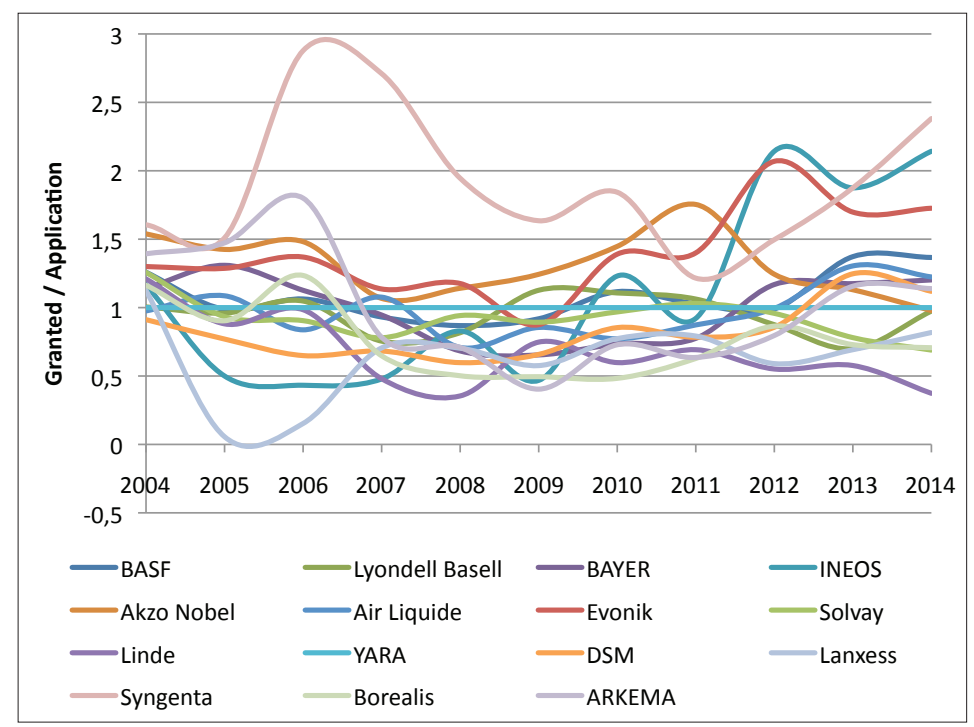

Data source: Thomson Innovation (2014). Authors' analysis

For the companies with the highest number of patents granted, Figure 18 shows the patents from a particular family that were first published in the EU as a percentage of the total published globally as the first patent of that family. In most cases, $50 \%$ of first patents are published in the EU, which may be due to the fact that research is mainly being done in EU laboratories or that companies feel that it is more important to protect their technology in the EU market. It is also interesting to see that BASF's share of the total number of first patents is falling, which may mean that their priorities are shifting to the emerging economies. 
Figure 18. Percentage of patents first published in EU compared to the total number of first patents published

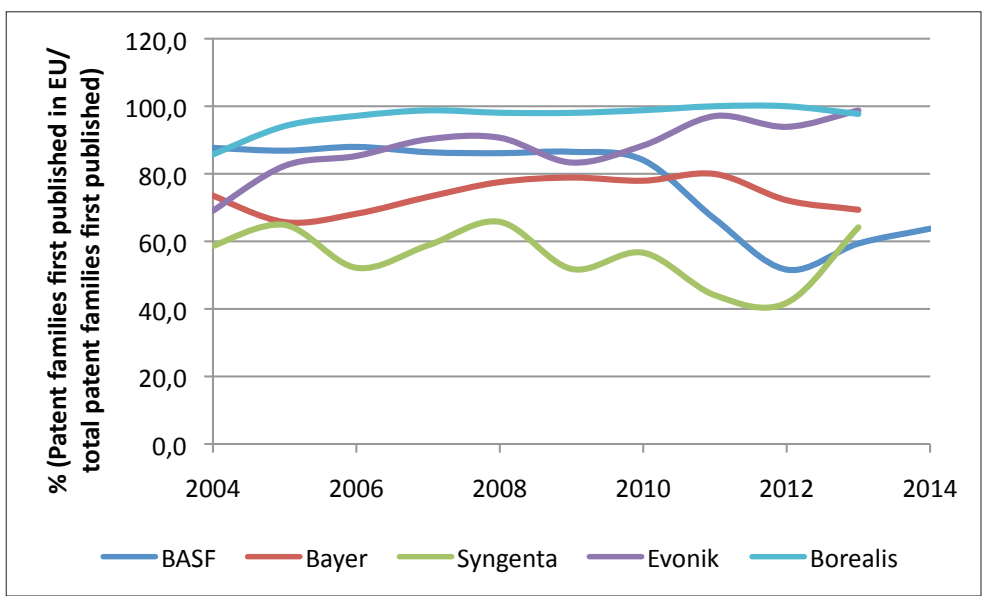

Data source: Thomson Innovation (2014). Authors' analysis

\section{Investment in research $\&$ development}

While innovation is more than research and development, the link between research in chemistry and innovation is particularly strong in the chemicals industry. Overall, the amount of research being done needs to be increased. In general, companies are urged to review their $\mathrm{R} \& \mathrm{D}$ plans and to extend corporate research programs to medium- and long-term objectives.

The European chemical industry is therefore uniquely placed to grow in the internal market as well as develop a global competitive advantage in developmentdriven and breakthrough innovations. Europe must retain a strong base in this sector, not only because of its economic weight, but also because of its ability to continually generate innovation critical to meeting the major challenges of modern societies. In the European Union, R\&D spending in terms of absolute value has remained almost constant while $R \& D$ spending as a percentage of sales has steadily declined (see figure 19). 
Figure 19. $R \& D$ spending and $R \& D$ spending as a percentage of total sales

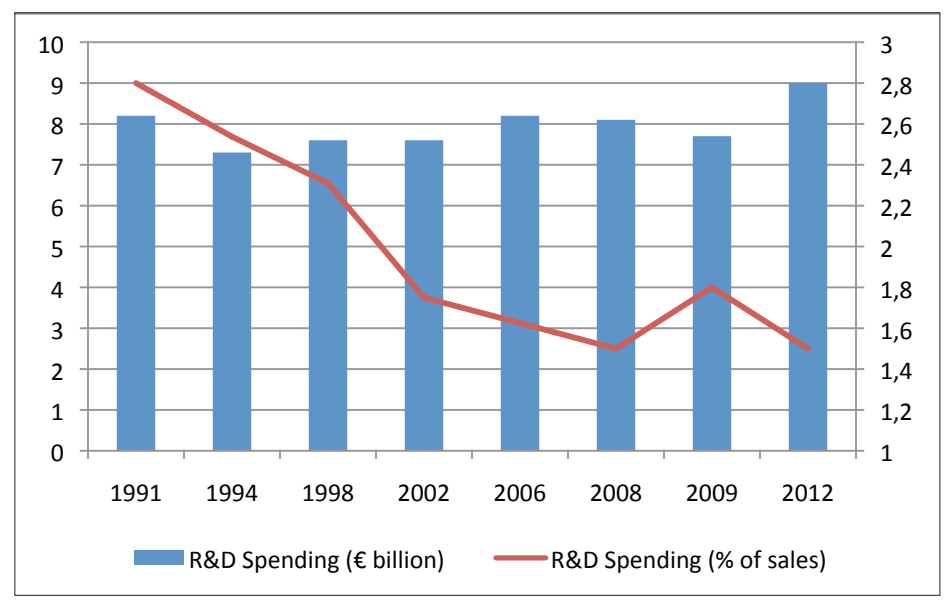

Data source: Cefic (2014). Graph: Author

Even though R\&D spending in absolute terms has remained almost the same over the years, it is still way ahead of other geographical regions. In China there was a three-fold increase in R\&D investment in 2012 compared to 2006. For other regions, R\&D spending has slightly increased.

\section{Figure 20. R\&D spending of different geographical regions} in 2012 compared to 2006

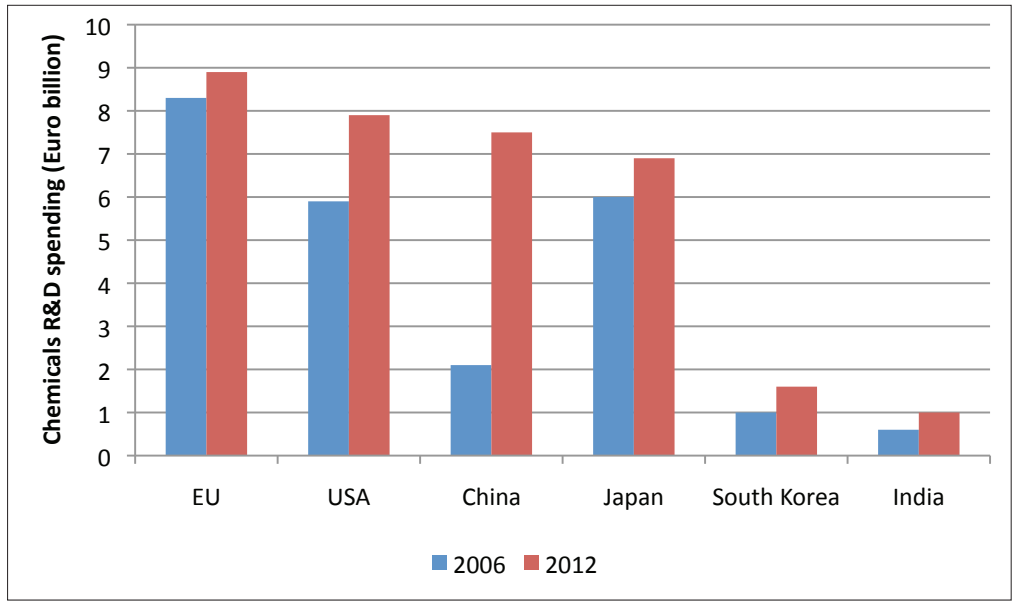

Data source: Cefic (2014) 
It is interesting to follow the strategy of the large European chemical companies through their investment in R\&D. BASF are the leader followed by Bayer. The other top investors in R\&D are Syngenta, Evonik, DSM and Akzo Nobel.

Figure 21. Investment in R\&D for the top European chemical companies

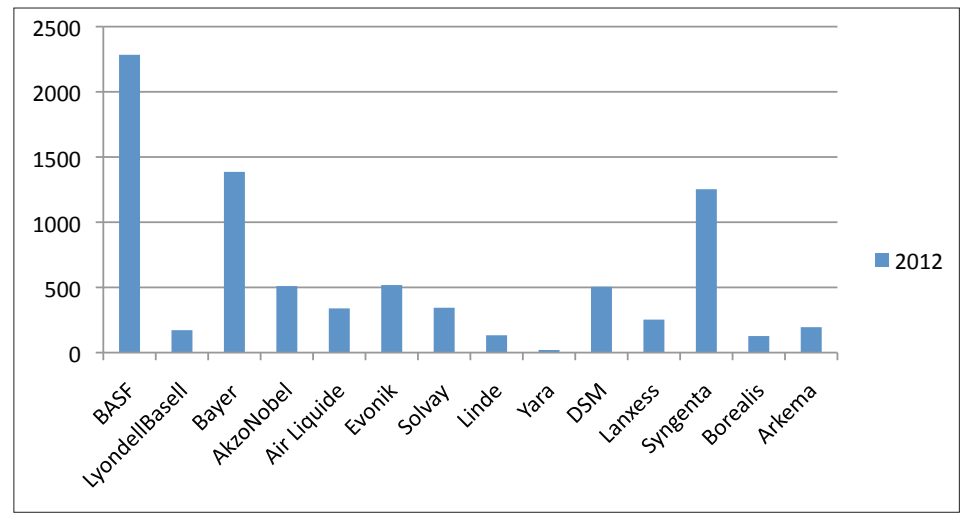

Data source: Davis (2013). Author's analysis

$R \& D$ intensity is the ratio of $R \& D$ investment to total sales expressed as a percentage. It is another measure of efficiency of R\&D activities. Syngenta has the highest R\&D intensity followed by Bayer and DSM.

Figure 22. R\&D intensity of the top chemical companies in Europe

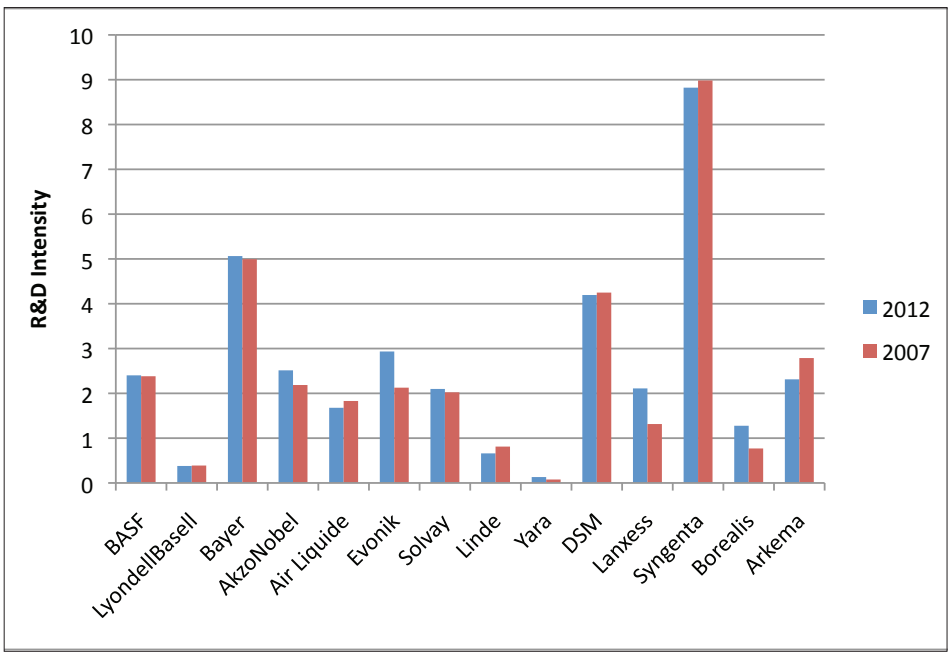

Data source: Davis (2013). Author's analysis 


\section{Merger and acquisition and its impact on innovation}

Research has shown that firms spend considerable resources on acquiring other firms in order to promote growth, improve efficiency, reduce risk and secure an advantage over competitors. Both M\&A and innovation are key factors in growth and competitive advantage and fundamental to a firm's competitive strategy. Traditionally, both components have been studied separately. Although we have a detailed understanding of the traditional objectives of $M \& A$, there has been relatively little research on the effect of M\&A on the innovation output of a firm although they are closely connected. This section focuses on the impact that mergers have on innovation.

Figure 23. Acquirer and target regions involved in acquisition deals of the chemical industry

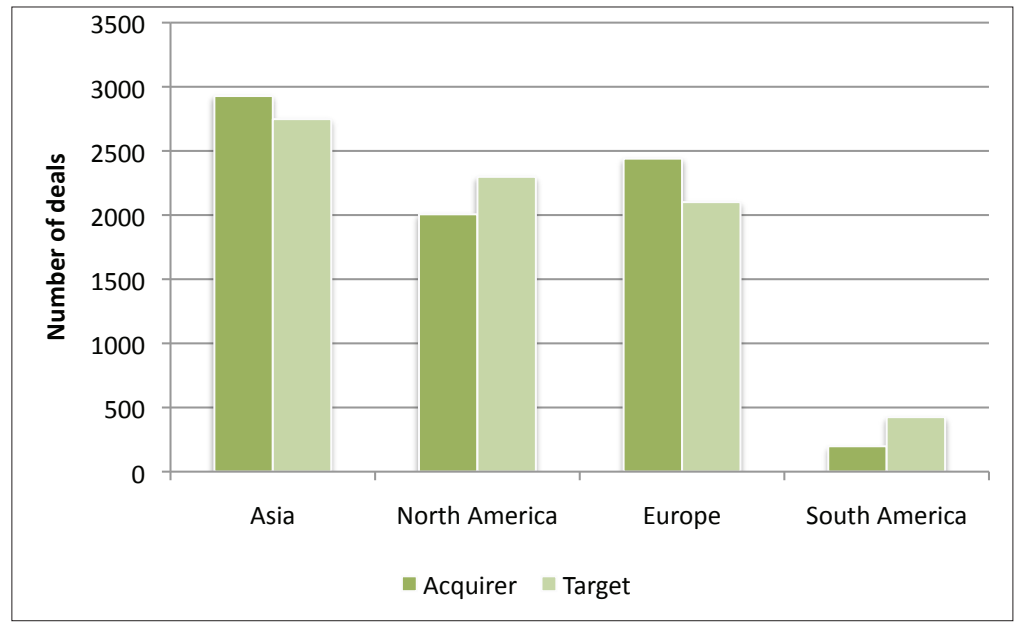

Data source: Thomsonone (2014). Graph: Author's calculation

Figure 24 breaks down the acquisition deals involving chemical companies over the last 10 years according to region. The dark green bars show the number of deals in which the acquirer was located in a particular geographical region. The fact that the acquirer is located in a particular geographical region does not mean that the target is also located there. The light green bars show the geographical location of the target company.

Most of the deals were in Asia followed by Europe and North America. As we have already discussed, the purpose of the acquisition is to grow in the current market or diversify in the newer market. In many of the deals the target 
companies are active in sectors other than the chemical sector. So, apart from market diversification, the purpose of these deals is to gain R\&D knowledge about the target companies' products. This is another way of innovating faster than by internal development.

Figure 24. Percentage of non-chemical company acquisition by top European chemical companies

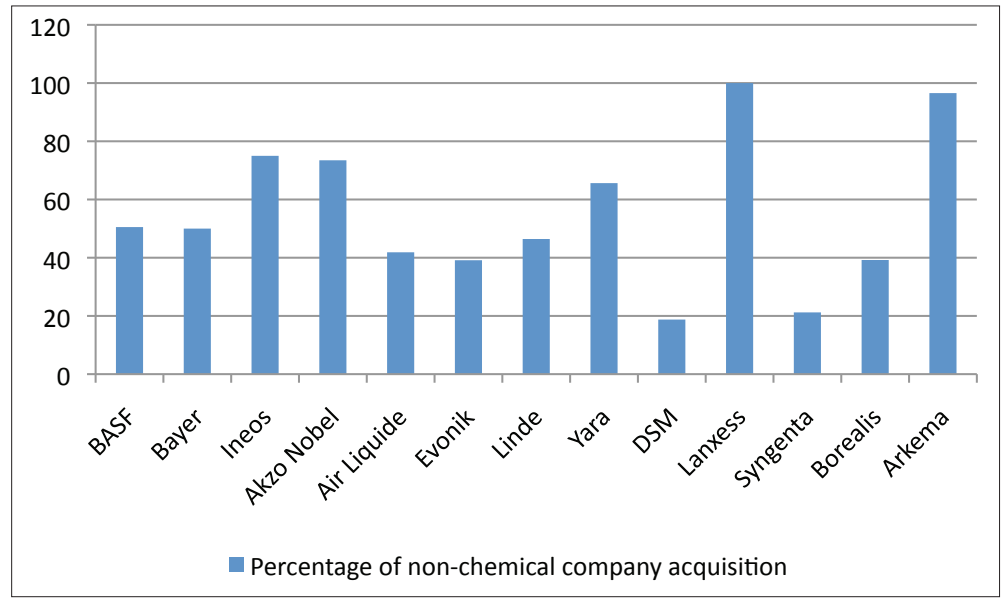

Data source: Thomsonone (2014). Graph: Author's calculation

Figure 25 shows the percentage of non-chemical company acquisition by the large European chemical companies for the last ten years. These companies have considerable expertise in the chemical and related sectors, but lack the know-how of the other sectors they want to step into. So they acquire companies from other sectors to quickly gain the technical knowledge and thus accelerate innovation. Lanxess and Arkema mainly stuck to their strategy of acquiring chemical companies, while almost $50 \%$ of the companies acquired by BASF, the largest chemical company in the world, were outside the chemical sector. A similar trend was observed for Bayer: $50 \%$ of the companies acquired were outside their core competences of chemicals and pharmaceuticals. So most of the large chemical companies in Europe are using acquisition as a tool for accessing the know-how and knowledge of sectors in which they did not have core competencies. 
Figure 25. Percentage of non-chemical companies acquired by the top chemical companies for the last 10 years

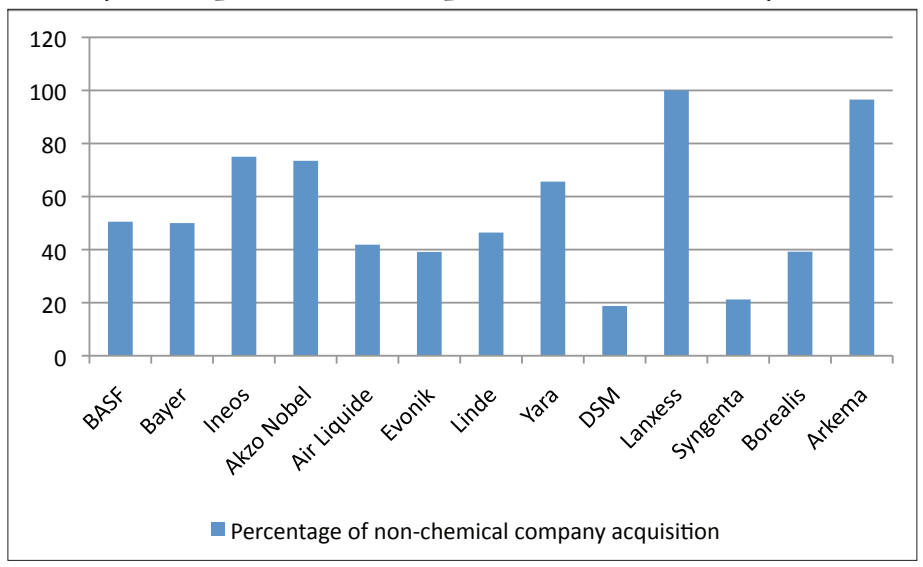

Source: Thomsonone (2014). Author's calculation and graph

\section{Industries, universities $\&$ research collaboration}

For an elite group of world-class research universities, this kind of strategic collaboration is top priority. The data analyzed show that all the top European chemical companies actively participate in EU-funded projects. The data for the last 20 years show that BASF is the company that most participates in EUfunded projects, followed by Bayer, Air Liquide and Evonik. EU funding not only drives these companies to participate in projects, but also encourages them to co-operate with research institutes, universities and even their competitors in driving research and innovation.

Figure 26. Total number of EU projects for the last 20 years in which the top European chemical companies have participated

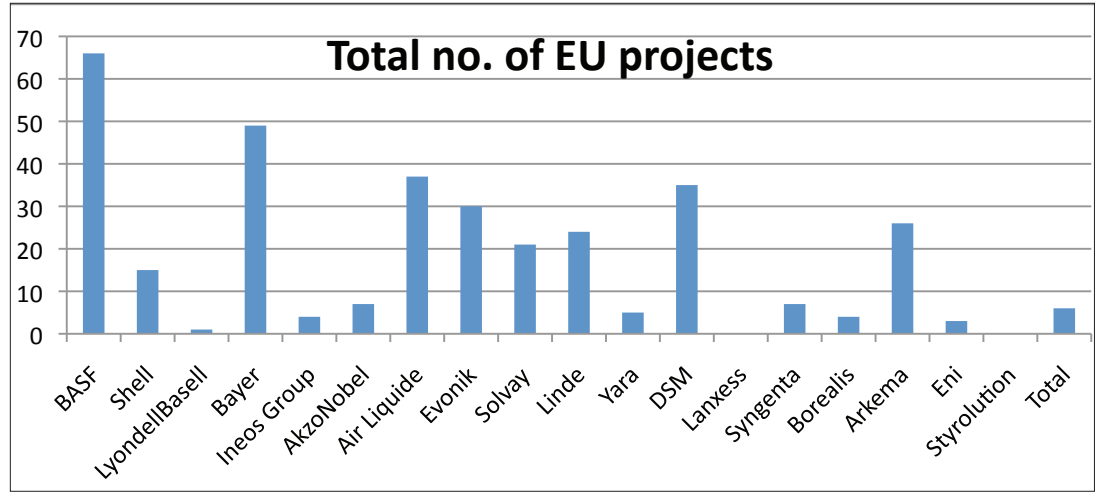

Data source: CORDIS1 (2014). Author's calculation and graph 
Each of the projects in which these companies have taken part was further analyzed in order to get a detailed understanding of the type of project and the partners. Although the type of project varies, if companies are involved, they tend to be more application oriented. Over $75 \%$ of the participants are government institutes or universities. The private companies involved in these projects were selected on the basis of their speciality areas (for example, Veneto Nanotech Spa from Italy, who specialize in nano-technology). This type of project drives research and innovation forward but the results are highly unlikely to be patented, because of the number of partners and the openness of the projects. Another example of BASF's participation in EU projects that involve fundamental research is "Developing the Next Generation of Biocatalysts for Industrial Chemical Synthesis". A group of industrial and academic partners had identified the key technology fields of amine synthesis, polymers from renewable resources, glycoscience and wider oxidase application as four key areas in which the next generation of biocatalysts will lead to improvements in both the economic and environmental performance of the chemical manufacturing industries. Most of the partners in this project are universities, but some private companies are also involved. Most of these are small, but highly specialized in the field of the project.

In some cases, two different entities of the same company can be partners in a project (for example, "The Plant Cell Wall Training Consortium" in which Bayer Bioscience and Bayer Cropscience are both involved). It is common for these big chemical companies not to participate in these projects with a single entity; rather they participate either as an individual business or as the same company from a different region. A more in-depth analysis of how these companies participate reveals a distinct trend. Some companies participate more with government organizations while others participate with both private and government organizations. By government organizations, we mean universities, colleges and publicly funded research institutes. Figure 27 shows the ratio between private and government participants in EU projects. 
Figure 27. Private and government partners in EU projects involving top European chemical companies

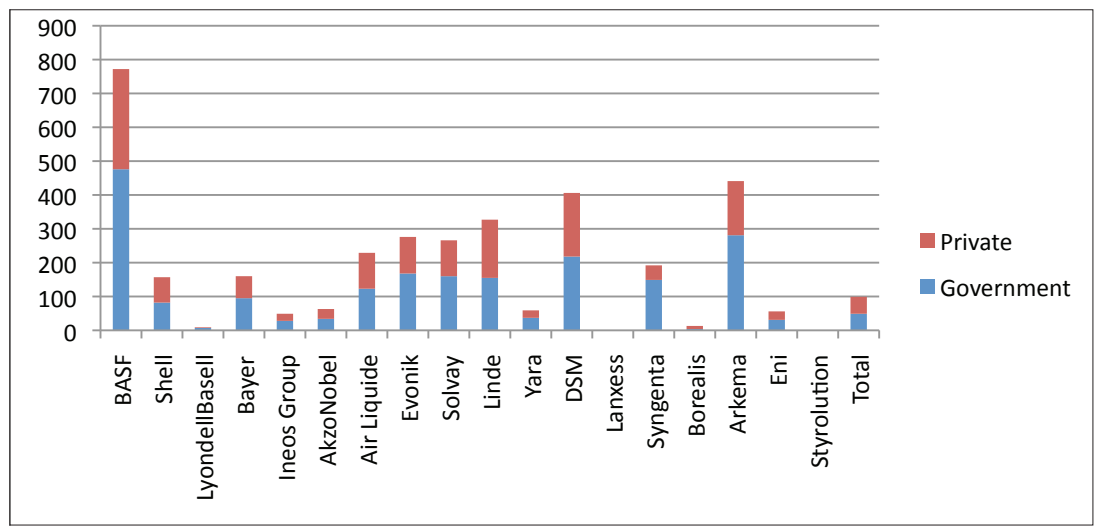

Data source: CORDIS1 (2014). Author's calculation and graph

Figure 28 shows that in these EU projects, in which one of the partners is a company being studied here, $40-70 \%$ of the participants are from private-sector companies.

Figure 28. Percentage of private companies in EU projects

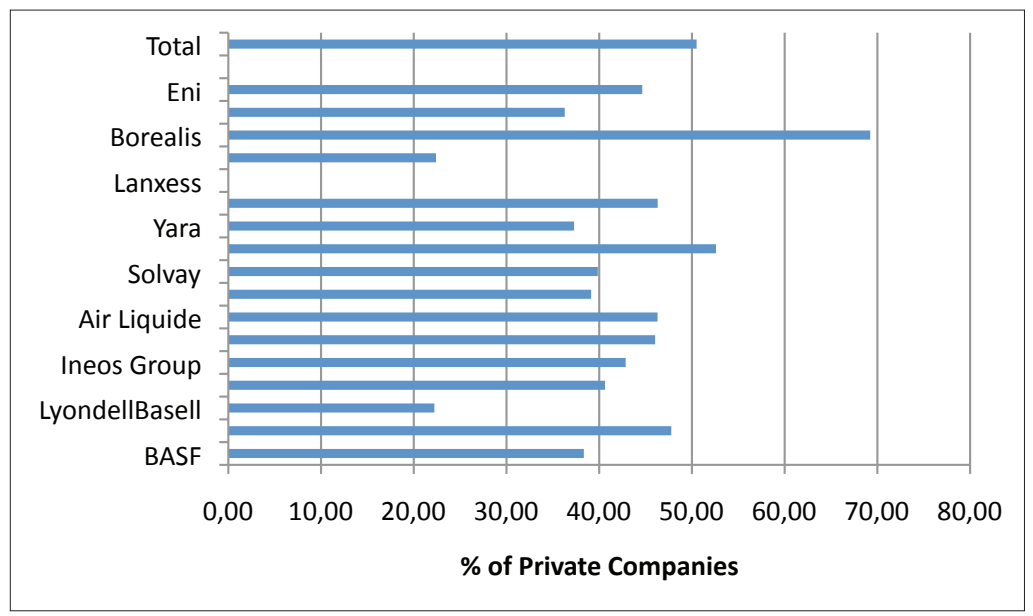

Data source: CORDIS1 (2014). Author's calculation and graph

Although the top chemical companies take part in a lot of EU-funded projects, they generally want to be participants rather than coordinators. In most cases they coordinate less than $20 \%$ of the projects they participate in. This 
may be due to the fact that coordination of EU projects involves a significant investment in resources. The only company which is somewhat the exception is Akzo Nobel,the coordinator of almost $56 \%$ of all the projects they participate in (figure 6).

Figure 29. Percentage of EU projects in which the top chemical companies participated and coordinated

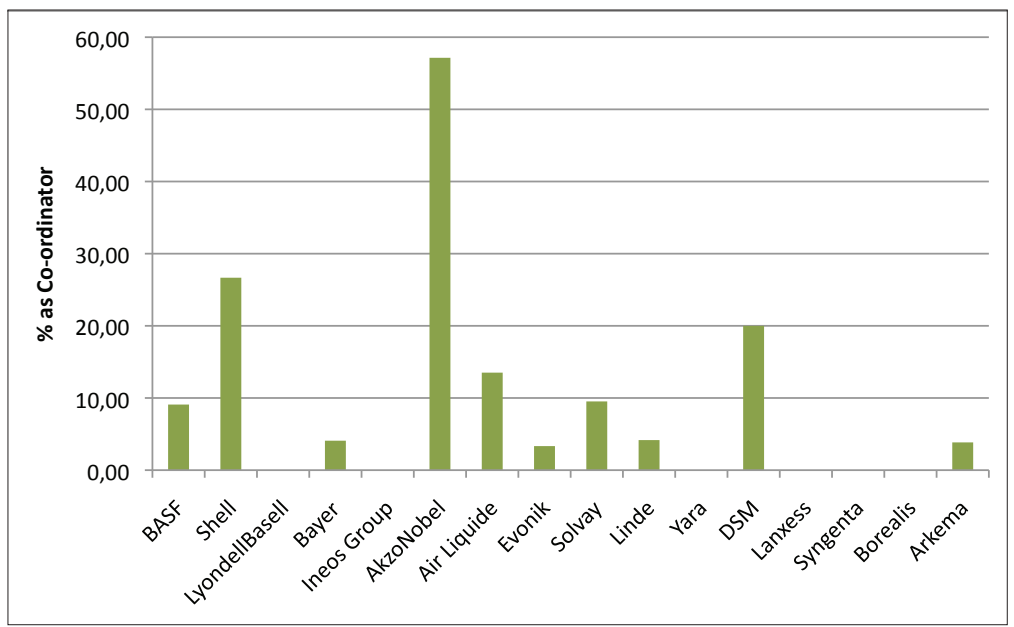

Data source: CORDIS1 (2014).Author's calculation and graph

\section{European chemical clusters and geographical distribution of chemical companies: impact on innovation}

The chemical clusters in Europe are concentrated in a few specific regions. This may be due to specific government policy or the suitability of the environment for growth. Whatever the case may be, though, clusters have a clear influence on the region in which they are located and the region, in turn, provides them with a particular character. 
Figure 30. Number of EU patents granted in chemistry and chemical engineering for the last five years

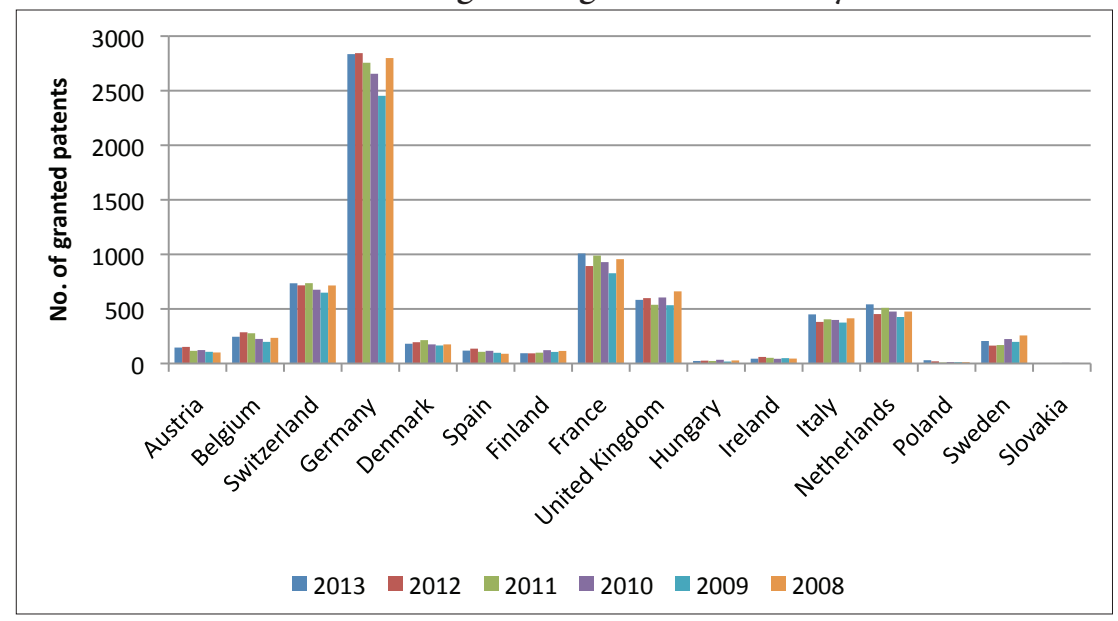

Source: European Patent Office (2013). Author's calculation and graph

It is interesting to see how innovation in terms of number of patents granted is distributed over the European countries. We saw earlier that Germany has the largest number of clusters (44) which account for $47 \%$ of all European clusters. In terms of EU patents granted in chemistry and chemical engineering, Germany has the largest number (2835), which is around $40 \%$ of the total number of EU chemical patents for the year 2013. France holds the second largest number of all EU chemical clusters (11\%) while it has $14 \%$ of all EU granted patents. So there is a direct relation between the number of clusters in a particular country and the number of EU patents granted in chemistry and chemical engineering.

Table 2. The distribution of clusters and EU patents granted over different European countries in 2013

\begin{tabular}{|l|c|c|c|c|}
\hline Country & $\begin{array}{c}\text { Number } \\
\text { of clusters }\end{array}$ & $\begin{array}{c}\text { \% of total } \\
\text { clusters }\end{array}$ & $\begin{array}{c}\text { Patents granted } \\
\mathbf{2 0 1 3}\end{array}$ & $\begin{array}{c}\text { \% of patents } \\
\text { granted }\end{array}$ \\
\hline Austria & 3 & 3.23 & 146 & 2.02 \\
\hline Denmark & 1 & 1.08 & 181 & 2.50 \\
\hline The Netherlands & 7 & 7.53 & 542 & 7.49 \\
\hline Spain & 3 & 3.23 & 118 & 1.63 \\
\hline Slovakia & 1 & 1.08 & 1 & 0.01 \\
\hline Hungary & 1 & 1.08 & 23 & 0.32 \\
\hline
\end{tabular}




\begin{tabular}{|l|c|c|c|c|}
\hline Country & $\begin{array}{c}\text { Number } \\
\text { of clusters }\end{array}$ & $\begin{array}{c}\text { \% of total } \\
\text { clusters }\end{array}$ & $\begin{array}{c}\text { Patents granted } \\
\mathbf{2 0 1 3}\end{array}$ & $\begin{array}{c}\text { \% of patents } \\
\text { granted }\end{array}$ \\
\hline Italy & 4 & 4.30 & 450 & 6.21 \\
\hline Switzerland & 2 & 2.15 & 735 & 10.15 \\
\hline France & 10 & 10.75 & 1008 & 13.92 \\
\hline Poland & 3 & 3.23 & 30 & 0.41 \\
\hline Finland & 2 & 2.15 & 94 & 1.30 \\
\hline Sweden & 2 & 2.15 & 206 & 2.84 \\
\hline Belgium & 3 & 3.23 & 245 & 3.38 \\
\hline United Kingdom & 6 & 6.45 & 583 & 8.05 \\
\hline Germany & 44 & 47.31 & 2835 & 39.15 \\
\hline Ireland & 1 & 1.08 & 44 & 0.61 \\
\hline
\end{tabular}

Source: European Patent Office (2013). Author's calculation

The big exception to the relation stated above is Switzerland. It has two chemical clusters but accounts for over $10 \%$ of the patents granted. This may be because a considerable amount of research is done in specialized institutes and universities.

\section{Conclusion}

The European chemical industry supplies raw material to almost all industries and is mainly concentrated in six EU countries: Germany, France, UK, Netherlands, Spain and Belgium. The following are the conclusions of the current study:

1. The European chemical industry is in a difficult situation and is facing unprecedented challenges from other regions of the world.

The manufacture of chemical products is increasingly moving eastward, drawn by the economic growth and market opportunities in Asia, the Middle East and Russia. Production is getting more expensive due to costs of labor and resources. The European chemical industry's share of world chemical sales declined from $29.8 \%$ in 2001 to $19.6 \%$ in 2011, which translates into a $34 \%$ decline over a period of 10 years. The value of the stock over the last ten years shows that the financial crisis of 2007-08 has severely affected the chemical industry and particularly the European chemical industry. Since the European chemical industry supplies all EU industrial sectors, including construction, its strategies impact directly on downstream chemical users. 
2. Europe still plays a key role in the global chemical industry.

The EU is still the leading world force in the chemical industry: it is home to 19 of the top 50 global chemical companies. Asia is in second place with 16 . Data for 2013-14 confirms that the European chemical industry has made a significant recovery. Although China has emerged as the biggest chemical producer, 8 of the top 30 major chemical-producing countries are European, generating chemical sales of EUR 480 billion. In Europe, Germany is the largest producer of chemicals, followed by France, Netherlands and Italy. The European chemical industry is moving towards specialty and consumer chemicals, which in 2011 accounted for $77 \%$ of the extra-EU chemical trade surplus. In Europe, even though large companies are only $3 \%$ of the total number of chemical companies, they employ $56 \%$ of the work force. BASF is the largest chemical company in terms of sales, almost double those of its nearest European competitor.

3. Patents as an innovation indicator did not show an upward trend for most companies.

Chemistry is the leading technical sector in terms of the number of patents granted by the European Patent Office. The areas that have most patents granted are fine organic chemistry, biochemistry and pharmaceuticals. Only five of the top selling European chemical companies feature in the list of the top 25 patent applications for fine organic chemistry in 2013, which suggests that they are moving into specialty chemicals. The number of patents granted to BASF, Bayer and Akzo Nobel has fallen over the last 14 years, which shows that they are not interested in protecting their technology in this market. Over the years BASF and Bayer have had the largest number of patents granted, which clearly shows their strategy of using patenting as a key tool for innovation and the protection of their technology. For most of the companies that were studied, the first patent of a patent family is applied for and granted by the European Patent Office. Some companies had very few patents granted, thus showing that not all companies have the same focus on innovation or patenting. BASF and Bayer had a downward patenting trend until 2009 and then there was sharp rise in the number of patents granted. This trend was also seen for many other companies analyzed. It can be concluded that the global crisis that hit the economy in 200708 had a negative effect on patenting and innovation.

4. The quality of research in most chemical companies is very high.

Large chemical companies have well-developed research and development departments. In most cases the ratio of patents applied for to patents granted for 
a particular year is between 0.5 and 1.5 , which suggests that patent applications are high quality and are readily granted. Research, then, is of a high level.

5. Although the EU chemical industry is shrinking its RED spending, almost all large chemical companies have been increasing their RED expenditure.

In the European Union, there has been a decline in R\&D spending in terms of both absolute value and percentages of sales but it is still way ahead of other geographical regions. In China there was a threefold increase in R\&D investment in 2012 compared to 2006, showing that R\&D was being given high priority. For other regions, R\&D spending has slightly increased. BASF spends the most on R\&D followed by Bayer, a distant second. BASF is the largest chemical company and this high spending on R\&D justifies its enormous R\&D infrastructure. Bayer invests heavily in research, especially in the pharmaceutical and crop science division. In 2012, Syngenta increased its R\&D expenditure compared to 2007 while Arkema and Linde both decreased their R\&D expenditure. Yara spent very little on R\&D in both the years. Syngenta has the highest R\&D intensity followed by Bayer and DSM. In most chemical companies, R\&D intensity is around 2\% (for example, BASF, AkzoNobal, Air Liquide, Evonik, Solvay, and Arkema). Bayer also shows a high R\&D intensity of $5 \%$ which can be attributed to their high investment in crop science and pharmaceutical products. LyondellBasell and Yara have very low R\&D intensities, which may be due to a very low level of investment in R\&D.

Bayer and BASF have a ratio of R\&D spending to patent application of around 2 while some companies have a ratio of below one. Companies whose ratio is low tend to show that their $R \& D$ is more efficient at generating patent applications or ideas. BASF has been investing in R\&D by increasing the number of people devoted to it. It should be noted that just after the financial crisis that hit in 2008, BASF increased its work force in R\&D, thus showing their strategy of R\&D expansion.

6. All the large chemical companies use merger $\mathcal{E}$ acquisition (MEA) to gain access to innovation.

Most merger and acquisition (M\&A) deals were entered into in Asia followed by Europe and North America. Apart from market diversification, the purpose of these deals is to gain R\&D knowledge about particular products. This is another way of gaining innovation faster than by internal development. When the acquiring chemical companies are located in Europe, they prefer to acquire companies that are also in Europe. Acquisition in other regions such as 
Asia and North America stands at a nominal 8 to $9 \%$. Over the last five years, acquisition has largely focused on non-chemical companies, which shows that these companies are trying to diversify and acquire know-how which is not part of their core competencies. Such companies as BASF, Air Liquide, Ineos, Evonik and Solvay are strongly inclined to acquire European companies while others such as Bayer, DSM and Arkema tend to acquire more globally. The companies have considerable expertise in the chemical industry and related sectors, but lack the know-how of the other sectors they wish to enter. So they acquire companies from other sectors to quickly gain technical knowledge and accelerate innovation. Lanxess and Arkema mainly stick to a strategy of acquiring other chemical companies. BASF, however, the largest chemical company in the world, is making $50 \%$ of its acquisitions outside the chemical sector. A similar trend has been observed for Bayer: recently the company was granted the highest number of patents for the last ten years. And $50 \%$ of the companies they acquired were outside their sector of expertise (chemicals and pharmaceuticals). So most of the large chemical companies in Europe are using acquisition as a tool for acquiring know-how and knowledge from sectors in which they do not have expertise.

7. Industry-academia collaboration is a way to generate innovation in the chemical industry in Europe.

All the top European chemical companies actively participate in EU-funded projects. The data for the last 20 years shows that BASF is the company that most participates in EU-funded projects followed by Bayer, Air Liquide and Evonik. Although funding acts as a stimulus for companies to take part in EU projects, they are also willing to co-operate not only with research institutes and universities but also with their competitors to drive research and innovation. Over $75 \%$ of the participants in EU projects are government institutes or universities. It is common for large chemical companies not to participate in these projects with a single entity; rather they participate either as an individual business or as the same company from a different region (for example, BASF Agro, BASF SE etc.). Some companies participate more with government organizations while others participate with both private and government organizations such as universities, colleges and publicly funded research institutes. Although the top chemical companies participate in a lot of EU-funded projects, they generally want to be participants rather than coordinators. In most cases they coordinate less than $20 \%$ of the projects they participate in. This may be due to the fact that coordination of EU projects involves a significant investment in resources. The 
only company which is somewhat the exception is Akzo Nobel, the coordinator of almost $56 \%$ of all the projects they participate in.

8. Chemical clusters and geographical distribution of the chemical companies play a significant role in generating innovation.

In Europe, there are over 300 chemical production sites which are located in clusters. Germany has the largest number of chemical clusters followed by France in a distant second place. Clusters do play a significant role in driving innovation in the European chemical industry. Alexera, Port of Antwerp and Tarragona are good examples of clusters which have been actively playing a role in innovation. EU patents in chemistry and chemical engineering are not uniformly distributed over the region. Germany is home to the largest number of EU patents in chemistry followed by France, UK and Switzerland. There is also a strong relationship between the number of chemical clusters in a particular country and the number of patents granted for that country.

\section{Bibliography}

Abratt, R.; Lombert van Altena, A. (1993). «Determinants of Product Innovation in Speciality Chemical Companies». Industrial Marketing Management, 22, 169-175.

Achilladelis, B.; Schwarzkopf, A. and Cines, M. (1990). «The dynamics of technological innovation: the case of the chemical industry». Research policy: policy and management studies of science, technology and innovation, 19 (1), $1-34$.

Arora, A.; Landau R. and Rosenberg, N. (1998). Chemicals and Long Term Economic Growth. New York: John Wiley and Sons.

Arvanitis, R. and Villavicencio, D. (2000). Learning and Innovation in the Chemical Industry. Developing Innovation Systems: London, Continuum.

ATKearney (2012). Emerging and Established Markets Coverage. Retrieved from ATKearney website: <https;//www.atkearney.com/mergers-acquisitions/ ideas-insights/featured-article/-/asset_publisher/4rTTGHNzeaaK/ content/emerging-and-established-markets-converge/10192>.

Cefic (2013). «Facts and Figures 2012». Retrieved from <http://www.cefic. org/Facts-and-Figures/ $>$.

Cefric (2013). The European Chemical Industry Council: Facts and Figures 2012. Retrieved from <http://www.cefic.org/Facts-and-Figures/ >.

Chesbrough, H. (2006). Open Innovation: The New Imperative for Creating and Profiting from Technology. Harvard Business School Publishing Corporation. 
Colombo, M*; Garrone, P. (1996). «Technlogical cooperative agreements and firm's R\&D intensity: A note on causality relations». Research Policy, 25, 923-932.

Cоцомво, U. (1980). «A viewpoint on innovation and the chemical industry». Research Policy, 9, 204-231.

Cоцомво, U. (1986). "Research, Innovation and Renewal in the chemical industry». Futures, 18(2), 170-177. doi: 10.1016/0016-3287(86)90096-0.

Cooper, G.R.; Kleinschmidt, J.E. (1993). «New-Product Success in the Chemical Industry». Industrial Marketing Management, 22, 85-99.

CORDIS 1 (2014). The primary information source for EU-funded projects since 1990. Retrieved from < http://cordis.europa.eu/projects/home_en.html>.

CORDIS (2014). Individual European Technology Platform. Retrieved from <http://cordis.europa.eu/technology-platforms/individual_en.html>.

Dal Pont, J.; Potier, O. and Camargo, M. (2013). Process Engineering and Industrial Management (pp. 371-96). Wiley.

Davis, N. (2013). ICIS Top 100 chemical companies. Retreived from ICIS Chemical Business website: <http://img.en25.com/Web/ICIS/FC0211_ CHEM_201309.pdf>.

ECSPP (2014). Chemical Parks in Europe. Retrieved from <https:// chemicalparks.eu/sites $>$.

European Cluster Observatory (2014). Clusters at your fingertips. Retreived from < http: //www.clusterobservatory.eu/index.html>.

European Commission Enterprise and Industry (2009). Retreived from $<$ http://ec.europa.eu/enterprise/index_en.htm > .

European Patent Office (2013). European Patent Office Statistics - 2013. Retrieved from <http //www.epo.org/about-us/annual-reports-statistics/ statistics.html>.

European Patent Office (2014). European patents and patent applications-2013 statistics. Retrieved from <http://www.epo.org/about-us/ annual-reports-statistics/statistics.html $>$.

Eurostat (2013). Manufacture of chemicals and chemicalproductsstatisticsNACE Rev. 2. Retrieved from European Union, Brussels website: <http:// epp.eurostat.ec.europa.eu/statistics_explained/index.php/Manufacture of_chemicals_and_chemical_products_statistics_-_NACE_Rev.2 $>$.

Fagerberg, J. (2003). Innovation: A Guide to the Literature. Oxford Handbook of Innovation. Oxford University Press.

Heinzelbecker, K. (2005). «Futuring in the European Chemical Industry». Journal of Business Chemistry, 2(1). 
Hutcheson, P; Pearson, A.W; Ball, D.F. (1996). "Sources of technical innovation in the network of companies providing chemical process plant and equipment». Research Policy, 25, 25-41.

Johnson, D. (2001). «What is Innovation and Enterpreneurship? Lessons for Larger Organizations». Industrial and Commercial Training, 33(4), 135-140. Quinn, J. (1985). «Managing Innovation: Controlled Chaos». Harvard Business Review. Retreived from <http //papers.ssrn.com/sol3/papers.cfm?abstract_ $\mathrm{id}=1504499>$.

REN, T. (2009). «Barriers and drivers for process innovation in the petrochemical industry: A case study». Journal of Engineering and Technology Management. 26(4), pp. 285-304.

Specialchem (2012). The universal source of chemicals. Retreived from <http:// www.specialchem.com/>.

Stetter,J;; Lieb, F. (2000). «Innovation in Crop Protection: Trends in Research». Angewandte, 39, 1724-1744.

Thomson Innovation (2014). Thomson Innovation Database: Thomson Reuter. Retrieved from <https://www.thomsoninnovation.com/login>.

Thomsonone (2014). Thomson One Database: Thomson Reuter [Data file and database]. Retreived from <https;//www.thomsonone.com/ DirectoryServices/2006-04-01/Web.Public/Login.aspx?brandname =www. thomsonone. $\operatorname{com} \&$ version $=3.7 .9 .18833 \&$ protocol $=0>$.

Tullo, A. (2013). «Global Top 50C\&EN’s 2013 survey shows leading chemical firms are pausing after a period of growth». CEEN Chemical Engineering News, 91 (30), 13-16.

Walsh, V; Lodorfos, G. (2002). «Technological and Organizational Innovation». MPRA Paper No. 11539. Retreived from <http://mpra. ub.uni-muenchen.de/11539/1/>.

WALSH,V* (1984). «Invention and innovation in the chemical industry: Demandpull or discovery-push?». Research Policy, 13, 211-234. 